\title{
Efficacy of Rational Emotive Behavioural Therapy and Cognitive Behavior Therapy in Reducing Aggressive Behavior among Secondary School Students in Abia State
}

\author{
Ekechukwu Rosemary Obiagaeri (Ph.D) \\ Department of Educational Psychology, Guidance and Counselling, Faculty of Education, University of Port \\ Harcourt, Rivers State, Nigeria \\ *Corresponding Author: Ekechukwu Rosemary Obiagaeri, Department of Educational Psychology, \\ Guidance and Counselling, Faculty of Education, University of Port Harcourt, Rivers State, Nigeria
}

\begin{abstract}
The study investigated efficacy of rational emotive behavioural therapy and cognitive behavior therapy in reducing aggressive behavior among secondary school students. The design adopted for the study was a quasi-experimental. The population for the study was 100 participants who showed tendency towards developing aggressive behaviour. Buss-Perry Scale for Aggressive Behaviour (BSAB) was used to collect data for this study. Two research questions as well as two hypotheses were formulated for the study. The data collected were analyzed using mean and standard deviation statistics for the research questions while the hypotheses were tested with a paired t-test statistics. The data analyzed revealed that, REBT and CBT is an effective and rewarding technique in the treatment of aggressive behavior among secondary school adolescents. Based on the findings, it was recommended that; Aggressive students should be encouraged to receive psychotherapeutic trainings like REBT and CBT. Counsellors should be well equipped in this area of using this two therapeutic skills. Also, Parents, significant others, stakeholders in the school, andadult members of the family should be encouraged to maintain and live a peaceful and healthy family relationship.
\end{abstract}

Keywords: REBT, CBT, Aggressive Behaviour

\section{INTRODUCTION}

Aggressive behaviour among students is considered a behavioural disorder; such behaviour involves physical violence against students and teachers. It includes the use of abusive language, bossiness, tantrums and emotional outbursts. Aggressive behaviour does not only disrupt classroom instructions, but also affects the physical and professional well-being of the teacher. Paul-Cookey and Iwuama (2011) observed that aggression is one of the major worldwide concerns in all segments of society. People frequently read or hear about gang battles, shootings, dating violence, bombings or actually become victims of such actions ( Ekechukwu, 2014). These events are some of the most extreme examples of the aggression that take place every day among adolescents.

Aggressiveness in this study refers to any behaviour intended to hurt other people. It is the use of physical force with the intention to damage or injure. It involves acts intended to kill or destroy. Cookey and Iwuama (2011) see aggression among secondary school students as all forms of youth violent acts perpetrated within the school setting which affects the schooling process. The state of aggressiveness in Nigeria and in Abia State in particular has reached alarming state that they have become worrisome to all stakeholders in the educational sector. Poju (2002) maintained that, violent adolescents show a pattern of childhood aggressive behaviour, which is often missed or disregarded as a passing phase in their developmental stage. Bono, and Judge (2004) found that adolescents from father-absent households usually harbor feelings of hostility, associate with deviant peers and get involved in negative activities. The increased risks of adverse outcomes for adolescent who live apart from their biological fathers appear to occur regardless of race, and educational background.

Carver and Scheier (2000) explained that, by a year and half, children are physically aggressive toward siblings, peers, and adults, but the vast majority will unlearn this attitude based on the cues they receive from their environment. This fact is important because it establishes the possibility of transferring behaviour from one generation to the other, which places the quality of parental care at 
the heart of aggressive behaviour. This aggressive behaviour has declined as the family unit disintegrates from the dissembling force of modern society that places personal rights and privileges above the family's collective wellbeing. Research has clearly shown that mothers' high level of antisocial behaviour before the end of high school tends to be followed by their children's high levels of physical aggression in early childhood (Anderson, 2004). A child that has low intelligence quotient is likely to adopt aggressive behaviour to resolve conflict that naturally would have been amenable to mental manipulation (Kotch, Lewis, Hussey, English, Thompson, Litrownik, Runyan, Bangdiwala, Margolis and Dubowitz, 2008). Even, the child's emotional qualities are early pointers to poor behaviour.

Children that exhibit lack of empathy and are fearless and more prone to aggressive behaviour. . Empathy is a social skill that helps the adolescents to check mate their relationship with others. It also helps to improve the quality of life and social intelligence as well as emotional intelligence of an individual. (Ekechukwu, 2017). Researchers have come to a conclusion that, aggressive adolescents at school show a very strong need for social recognition; they would like to be considered as powerful, socially accepted, different, and rebellious by their classmates. In other words, some authors suggest that the desire for popularity, leadership, and power leads to the involvement of many adolescents in disruptive behaviours, providing them the opportunity to construct the social reputation they desire. In fact, it has been documented that aggressive adolescents normally show somewhat negative attitudes to institutional authorities such as the police, the law, and also the school and teachers (Amanda and Monica, 2004).Nevertheless, aggressive behaviour can be treated considering the fact that it is not inherited but learned. . Researchers in the past have searched for techniques that can be used to help adolescents who have aggressive behaviour tendencies. Some or none of them knew much about psychotherapies that are found to be effective to some extent in helping the adolescents. Furthermore, aggression has emotional symptoms which may be controlled by Rational emotive behavioural therapy (REBT) . Rational Emotive behavioural therapy may be used to reduce aggression, depression and other emotional maladjustment problems. (Ekechukwu, 2014).

REBT proponent holds that humans are prone to adopting irrational beliefs and behaviours which stand in the way of their achieving their goals and purposes. Most importantly, REBT maintains that, individuals are capable of changing their beliefs and philosophies profoundly, and thereby able to change radically their state of psychological health. In addition, psychological health, thought of inadequacy, worthlessness, hopelessness, self-blame and pessimism are symptoms of anger that interfere with normal functioning, so that the individuals has trouble concentrating and making decisions. These then lead to emotional, behavioural and cognitive consequences. Although, we may not always be aware of our thoughts, they nevertheless can have a long effect on how we feel and behave in response to a particular situation or event. (Albert Ellis cited in Ekechukwu, 2014).

From cognitive behaviour therapists' point of view, people have the capacity to be rational or irrational, erroneous or realistic in their thinking. In fact, the way of thinking about their experiences determines how they feel about those experiences and what they will do. According to cognitive behaviour therapy, what determines individuals' moods and subsequent behaviours is the way they structure and interpret experiences. Seeing and perceiving negatively are purported to cause negative feelings and debilitative behaviours. A characteristic of cognitive behaviour therapy (CBT) is that it looks for errors in thinking and events that are misinterpreted leading to negative thoughts that lead to outburst of anger. CBT tries to change ways of thinking so that things which clients found to be the cause of anger may not be the cause any longer. The goals of therapy are to assist people in minimizing emotional disturbances, decreasing self-defeating behaviours, and becoming more selfactualized so that they lead a happier existence (Ellis, 2003a). Major sub-goals are to help individuals think more clearly and rationally, feel more appropriately, and act more efficiently in achieving goals of living happily.

They deal with unhealthy negative feeling such as anger, depression, anxiety, and worthlessness by using an effective rational emotive behaviour philosophy. It is in the light of these that the researcher found it very necessary to investigate into the efficacy of rational emotive behavioural therapy (REBT) and cognitive behaviour therapy (CBT) techniques in reducing aggressive behaviour among secondary school adolescents in Abia State. 
People frequently read or hear about gang battles, shootings, bombings or actually become victims of such action. Aggressive behaviour among students may result in destruction of school property, fighting, students can injure themselves in the process of carrying this aggressiveness; it also results in rioting and closure of schools. Relational aggression can be devastating. Loss of friendships and social standing are psychologically-damaging, the isolation and harassment can be unbearable for the victim. Moreover, female students are easily wounded or harmed because of the high value they typically place on friendships. As a result, victims sometimes feel that they are in part to blame and therefore deserve to be isolated. Finally, aggressive behaviour may give rise to poor school attendance disobedient to the teachers, lateness and poor academic performance and academic failures.

\section{Aim And OBJectives Of The Study}

The main aim of this study is to examine the efficacy of rational emotive behavioural therapy and cognitive behaviour therapy in reducing aggressive behaviour among secondary school students in Abia State. Specifically, the study will achieve the following objectives: to

1. Determine the efficacy of rational emotive behavioural therapy for reducing aggressive behaviour among secondary school students as measured by their pre-test and post-test mean scores.

2. Examine the efficacy of cognitive behavior therapy for reducing aggressive behaviour among secondary school students as measured by their pre-test and post-test mean scores.

\section{Research Questions}

1. What is the difference between the pretest and posttest mean scores of aggressive students treated with rational emotive behavioural therapy?

2. What is the difference between the pretest and posttest mean scores of aggressive students treated with cognitive behaviour therapy?

\section{Hypotheses}

1. There is no significant difference between the pre-test and post-test mean scores of aggressive students treated with rational emotive behavioural therapy

2. There is no significant difference between the pre-test and post-test mean scores of aggressive students treated with cognitive behaviour therapy

\section{Research Method And Procedures}

A sample of 100 respondents was drawn from the target population through a non-probability purposive sampling technique. Balloting system was used to assign subjects into either experimental groups or control group. A standardized instrument tagged "Buss-Perry Scale for Aggressive Behaviour (BSAB) was used to collect data for this study. The test re-test was used to determine reliability and the scores obtained was 0.83 . The researcher administered the questionnaire personally to enhance large returns.

\section{Data Analysis}

The research questions were answered with mean and standard deviation statistics. The null hypotheses were tested with paired t-test.

Research Question 1: what is the difference between the pre-test and post-test mean scores of aggressive students treated with rational emotive behavioural therapy?

Hypothesis 1: There is no significant difference between the pre-test an post-test mean scores of aggressive students treated with rational emotive behavioural therapy

To answer this research question and test its related null hypothesis, mean, standard deviation and paired t-test were employed. After the analysis, the results obtained were summarized and presented as in table 4.1 below;

Table4.1. Paired t-test analysis on the difference between the pre-test and post-test mean scores of aggressive students treated with rational emotive behavioural therapy

\begin{tabular}{|l|l|l|l|l|l|l|l|l|l|l|l|}
\hline REBT & N & $\bar{X}$ & & SD & & Df & & t-cal & Sig \\
\hline Pre-test & 50 & 29.44 & 3.41 & & 49 & & 33.88 & .000 \\
\hline Post test & 50 & 9.86 & 2.99 & & & & & \\
\hline
\end{tabular}


The results in table 4.1 shows that, the mean scores of the group treated with REBT during their pretest and post test scores on aggression indicated that they scored higher on aggressive behaviour scale during their pre-test than in their post-test. When this mean score was subjected to paired t-test, it was found that, the $\mathrm{t}$-value of 33.88 obtained was significant at $\mathrm{P} \leq .05$ level of significance. Hence, REBT had significant influence in reducing aggressive behaviour among students. Based the result, the null hypothesis of no significant effect of is rejected, while the alternate hypothesis accepted (see table 4.1).

Research Question 2: what is the difference between the pre-test and post-test mean scores of aggressive students treated with cognitive behaviour therapy?

Hypothesis 2: There is no significant difference between the pre-test and post-test mean scores of aggressive students treated with cognitive behaviour therapy

To answer this research question and test its related null hypothesis, mean, standard deviation and paired t-test were employed. After the analysis, the results obtained were summarized and presented as in table 4.2 below;

Table4.2. Paired t-test analysis on the difference between the pre-test and post-test mean scores of aggressive students treated with cognitive behaviour therapy

\begin{tabular}{|l|l|l|l|l|l|l|l|l|l|}
\hline CBT & N & & $\bar{X}$ & SD & & Df & & t-cal & Sig \\
\hline Pre-test & 50 & & 29.98 & 2.48 & 49 & & 47.40 & .000 \\
\hline Post test & 50 & & 10.78 & 1.82 & & & & & \\
\hline
\end{tabular}

The result in table 4.2 shows the pre-test and post-test mean scores of aggressive students treated with $\mathrm{CBT} ; \bar{X}=29.98$ and $\mathrm{SD}=2.48, \bar{X}=10.78$, and $\mathrm{SD}=1.82$ respectively. When these mean scores were subjected to paired samples t-test, it was found that a calculated t-value 47.40 was significant at $\mathrm{P} \leq .05$ level of significance. Thus, a significant influence of CBT on the reduction of aggression among secondary school adolescents was found. Hence, the null hypothesis of no significant difference between the pre-test and post-test mean scores was rejected while the alternate hypothesis is accepted (see table 4.2).

\section{RESEARCH FINDINGS AND DISCUSSION}

\subsection{Efficacy of Rational Emotive Behavioural Therapy in reducing level of Aggression among Students}

The results in table 4.1 showed the pretest and posttest mean scores of the students treated with rational emotive behavioural therapy were 29.44 and 9.86 respectively. This is to show that the students scored higher in their pretest mean score than in their posttest mean score. This is an indication that their aggressive behavior level reduced after their treatment. When these mean differences were subjected to a paired t-test, it was found that REBT had significant efficacy in reducing aggressive behavior among secondary school students. This finding did not appear as a surprise because; REBT is a treatment consisting a combination of three different types of technique i.e. cognitive, behavioural and emotive. It is used to help an individual feel better physically, emotionally and to engage in healthier behaviours. And it is an active treatment for coping with life's difficulties.

This result of this finding supported that of Moore (1999) who found that REBT has the efficacy on the improvement of at-risk adolescents in relation to their irrational thinking, attitude to school, social competence and anti-social behavior. To some extent, the finding from this present study differs somehow from that of Moore because he did not carry out his study on the efficacy of REBT on aggressive behavior rather; his work was on the respondents' irrational thinking, attitude to school and social competence and anti-social behaviours.

In another aspect, the finding from this study supported the findings from the work of Morris (1993) who found that REBT had the efficacy of changing conduct disorder among adolescents. However, the finding of the present study which revealed that REBT had the efficacy of reducing aggressive behavior among students may be attributed to the fact that aggression is a learned response to a 
Efficacy of Rational Emotive Behavioural Therapy and Cognitive Behavior Therapy in Reducing Aggressive Behavior among Secondary School Students in Abia State

particular circumstance and so can be modified with the help of psychotherapeutic strategy in which REBT is one.

\subsection{Efficacy of Cognitive Behaviour Therapy on Aggression reduction among Students}

The results in table 4.2 revealed that the pre-test mean scores of the students treated with CBT was higher than their posttest mean score on aggressive behavior scale. The mean scores are 29.98 and 10.78 respectively for pretest and posttest scores. This implies that, CBT was efficacious on the reduction of aggression among students. When this mean difference was subjected to paired t-test, a significant mean difference was obtained. This is because the $t$-cal value 47.40 was significant at level 0.000 which is lower than the chosen 0.05 level of probability.

The outcome of this finding was expected because; CBT is a therapeutic technique that is aimed at helping people to be aware of when they act, interpreted action, or behave in such a way that could distort their thinking. As a result, may help individuals to develop an alternative positive way of thinking and behaving which will in one way or the other help to reduce aggressive behaviour among individuals.

The finding of this study is in agreement with the result of an earlier study by Mclead (2008) who explained that; cognitive behavior therapy is empirically supported and has been seen to effectively help patients overcome a wide variety of maladaptive behaviours which aggression is allencompassing. The efficacy of CBT on the reduction of aggressive behavior among secondary school students was possible due to the fact that aggressive individuals are seen to have faulty and distorted thinking pattern. They may also think that they do not have any other way of showing how powerful and angry they can get whenever they are infuriated so in order to earn acceptance among their friends they tend to display their aggressive tendencies. On the other hand, aggression may be a learned behavior from their families or immediate environment. All these ways of thinking and feeling can be modified through psychotherapeutic method such as cognitive behavior therapy reason being that, CBT aims to help individuals become aware of when they make negative interpretations and of behavioural patterns which reinforce the distorted thinking. CBT helps to develop alternative ways of thinking and behaving which reduces the individual's level of aggressive behavior.

\section{CONCLUSION AND RECOMMENDATIONS}

The study aimed at determining the efficacy of rational emotive behavioural therapy and cognitive behavior therapy in reducing aggressive behavior among secondary school students in Abia state. Based on the data analysis, the result found that, REBT had significant influence in reducing aggressive behaviour among students. A significant influence of CBT on the reduction of aggression among secondary school adolescents was found that the students treated with REBT had mean scores of 65.35 and 57.23 for high and low SES family while those treated with CBT had mean scores of 64.16 and 61.53 respectively. From the foregoing therefore, it can be concluded that, aggressive students treated with REBT had the lowest level of aggressive behaviours followed by those treated with CBT. Based on the findings of this study, it was recommended among others that; Aggressive students should be encouraged to receive psychotherapeutic trainings like REBT and CBT. Furthermore, Parents and adult members of the family should be encouraged to maintain and live a peaceful and healthy family relationship.

\section{REFERENCES}

[1] Amanda, C. \& Monica, (2004). Gender differences in time use among adolescent in developing countries: Implications of Rising school enrolment rates.

[2] Anderson, J. B. (2004). Modifying maladaptive behaviour in schools. In A. I. Idowu (Ed.). Guidance and Counselling in Education. Ilorin: Indemac Ltd.

[3] Bono, J. E., and Judge, T. A. (2004): Personality and Transformational and Transactional Leadership: A Meta-Analysis. Journal of Applied Psychology.

[4] Carver, G., \& Scheier, E. (2000).Media and popular culture. In K. A. Renninger\& I. E. Sigel (Eds.), Handbook of child psychology: Vol. 4. Child psychology in practice (6th ed., pp. 817-863). Hoboken, NJ: Wiley.

[5] Ekechukwu . R.O. \& Onyekuru B.U. (2014),New Dawn In Counselling Psychology, In school and Non school Setting. Owerri. Career Publishers. 
Efficacy of Rational Emotive Behavioural Therapy and Cognitive Behavior Therapy in Reducing Aggressive Behavior among Secondary School Students in Abia State

[6] Ekechukwu. R.O. (2017). Correlates of Empathy Among Secondary school students in Rivers State, Nigeria. Educational International Research Journal Vol. 6 (5). November.

[7] Kotch JB, Lewis T, Hussey JM, English D, Thompson R, Litrownik AJ, Runyan DK, Bangdiwala SI, Margolis B, Dubowitz H (2008). Importance of Early Neglect for Childhood Aggression. Pediatrics

[8] Paul-Cookey,N.R \& Iwuama, B.C.( 2011) Comparism of forms and incidence of school violence among urban and rural secondary school students Journal Educational Psychology University of Port Harcourt

[9] Poju.A. (2002). Assault on the academy, A paper presented in March (2002) copied from the internet.

\section{AUTHOR'S BIOGRAPHY}

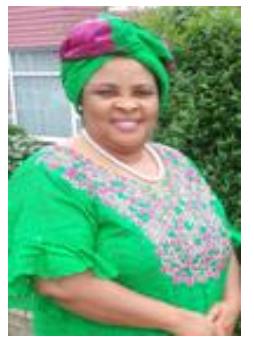

Dr Mrs Rosemary Ekechukwu, is a senior lecturer in the department of Educational Psychology, Guidance and Counselling, Faculty of Education. University of portharcourt. Rivers state. Nigeria. She is a prolific writer. She has authored scholarly articles in reputable international and National Journals. She has attended and presented papers in foreign and local workshops and conferences. She has edited and supervised many undergraduates and graduates students projects, desertations and thesis. She is a member of both local and foreign Researchers, Academics and psychological Associations. Which includes International society of Scientific and Behavioural Development (ISSBD), Counselling Association of Nigeria (CASSON), etc. She is currently working on Mental, Gerontological and community counselling, an area many counselling psychologists neglect.

Citation: Ekechukwu Rosemary Obiagaeri. " Efficacy of Rational Emotive Behavioural Therapy and Cognitive Behavior Therapy in Reducing Aggressive Behavior among Secondary School Students in Abia State

" International Journal of Humanities Social Sciences and Education (IJHSSE), vol 5, no. 1, 2018, pp. 77-82 doi: http://dx.doi.org/10.20431/2349-0381.0501012.

Copyright: (C) 2018 Authors. This is an open-access article distributed under the terms of the Creative Commons Attribution License, which permits unrestricted use, distribution, and reproduction in any medium, provided the original author and source are credited. 